\title{
Ценности и отношение к этнической культуре и традициям как предикторы субъективного благополучия русских и казахов
}

\author{
Раиль М. Шамионов ${ }^{1 *}$, Насия Ж. Султаниязова ${ }^{1,2}$ \\ ${ }^{1}$ Саратовский национальный исследовательский государственный университет имени \\ Н.Г. Чернышевского, г. Саратов, Российская Федерация \\ 2 Западно-Казахстанский инновационно-технологический университет, г. Уральск, \\ Республика Казахстан \\ ${ }^{*}$ E-mail: shamionov@mail.ru
}

\begin{abstract}
Аннотация
Ввеление. В статье обсужАаются результаты исследования предикторов субъективного благополучия представителей Авух этнических групп - русских и казахов России и Казахстана. Предполагается, что ценности, являясь продуктом социального творчества, обусловливают не только характер приспособления, но и вариации субъективного благополучия ^ичности, что происходит опосреАованно, через соответствие ценностей и реализуемой активности. Цель исслеАования заключается в анализе ценностей и отношения к этнической культуре и традициям как преАикторов субъективного благополучия.

Методы. Выборки организованы по пропорциональному принципу по 75 че^овек, всего 300 человек. Использованы: шкала удовлетворенности жизнью Э. Аинера в алаптации А. А. Аеонтьева, Е.Н. Осина; шкала субъективного счастья С. ^юбомирски и Х. Аеппер в адаптации А. А. Аеонтьева, Е.Н. Осина; шкала психо^огического благополучия К. Риффф в аАаптации А.В. Жуковской и Е.Г. Трошихиной; методика индивидуальных ценностей С. Шварца; авторские шкалы Аля анализа отношений к этнической культуре и традициям.
\end{abstract}

Результаты. Получены новые Аанные, раскрывающие характер детерминации субъективного благополучия в условиях обособления и интеграции этнических групп. Показано, что выраженность большинства ценностей имеют признаки сходства. У представителей титульной нации более весом показатель ценностей «самостоятельность: мысли», а у групп меньшинств этот показатель значимо ниже в обоих случаях. Выявлены сложные соотношения межАу ценностями, отношением к культуре и традициям и характеристиками субъективного благополучия Аичности. Ценности и отношение к этнической культуре и традициям выступают наиболее сильными предикторами психологического благополучия. ПреАставители титульных этносов характеризуются более определенной ценностной Аетерминацией уАовлетворенности жизнью и счастья. 
СОЦИАЛЬНАЯ ПСИХОЛОГИЯ

Обсужаение результатов. Авторы рассматривают полученные результаты сквозь призму происходящих изменений в Авух странах, характеризующих Аве противоположные тенденции - консолидации титульных этносов и принятие иАеологии мультикультурализма.

\title{
КАючевые слова
}

^ичность, этническая группа, субъективное благополучие, счастье, удовлетворенность жизнью, культура, традиции, ценности, отношение, преАиктор

\section{Основные положения}

- на основе сравнительного анализа выявлены схолство и различия выраженности ценностей в четырех группах респондентов - русских и казахов, проживающих в России и Казахстане;

- в результате регрессионного анализа установлены ценностные предикторы характеристик субъективного благополучия в разных выборках;

- в результате регрессионного анализа выявлены характеристики отношений к культуре, являющиеся наиболее важными переменными, оказывающими влияние на вариации характеристик субъективного благополучия в изучаемых выборках.

\section{Благодарности}

Исследование выполнено при финансовой поддержке РФФИ в рамках научного проекта № 18-013-00094.

\section{Для цитирования}

Шамионов Р.М., Султаниязова Н.Ж. Ценности и отношение к этнической культуре и традициям как предикторы субъективного благополучия русских и казахов // Российский психологический журнал. - 2018. - Т. 15, № 1. - С. 157-186. DOI: 10.21702/rpj.2018.1.8

Материалы статьи получены 25.01.2017

UDC 316.6:159.923

DOI: $10.21702 /$ rpj.2018.1.8

\section{Values and Attitudes to Ethnic Culture and Traditions as Predictors of Subjective Well-Being Among Russians and Kazakhs}

\author{
Rail M. Shamionov ${ }^{1 *}$, Nassiya Zh. Sultaniyazova ${ }^{1,2}$ \\ ${ }^{1}$ Saratov State University, Saratov, Russian Federation \\ ${ }^{2}$ West-Kazakhstan Innovative-Technological University, Uralsk, Republic of Kazakhstan \\ *Correspondence author. E-mail: shamionov@mail.ru
}




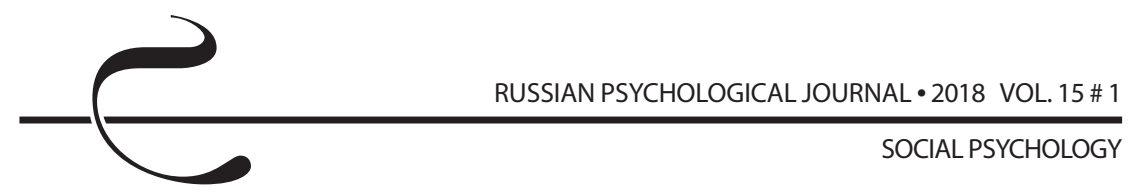

\section{Abstract}

Introduction. The article discusses the results of the study of the predictors of subjective well-being among representatives of two ethnic groups - Russians and Kazakhs from Russia and Kazakhstan. Values are the product of social creativity; they determine the type of adaptation, and also variations in the subjective well-being of the individual. This process occurs indirectly, through the correspondence of values and the realized activity. The main purpose of this study is to analyze values and attitudes to ethnic culture and traditions as predictors of subjective well-being.

Methods. These were the Satisfaction With Life Scale (E. Diener et al.) modified by D. A. Leont'ev and E.N. Osin; Subjective Happiness Scale (Lyubomirsky \& Lepper) modified by D. A. Leont'ev and E.N. Osin; the Ruff Scales of Psychological Well-Being modified by L. V. Zhukovskaya and E.G. Troshikhina; the Schwartz Value Inventory; authors' scales for revealing attitudes to ethnic culture and traditions. The study employed proportional sampling method; each sample comprised 75 persons $(n=300)$.

Results. The study revealed new data about subjective well-being in the conditions of isolation and integration of ethnic groups. Almost all of the investigated values were similar. The representatives of a titular nation had a higher level of the "Independence: thoughts" value; the minority groups had a significantly lower level of this value in both cases. Values and attitudes to ethnic culture and traditions were the strongest predictors of psychological well-being. More definite value determination of life satisfaction and happiness was inherent in the representatives of the titular ethnic groups.

Discussion. The paper considers the obtained results through the prism of ongoing changes in the two countries, characterizing two opposite tendencies - consolidation of titular ethnic groups and the adoption of multiculturalism.

\section{Keywords}

personality, ethnic group, subjective well-being, happiness, life satisfaction, culture, traditions, values, attitude, predictor

\section{Highlights}

- Comparative analysis revealed similarities and differences among values in the four groups of respondents - Russians and Kazakhs living in Russia and Kazakhstan.

- Regression analysis helped establish value predictors of subjective well-being in different samples.

- Regression analysis revealed the most important variables that affected the characteristics of subjective well-being in the studied samples; these were characteristics of attitudes to culture.

\section{Acknowledgments}

The study was supported by the Russian Foundation for Basic Research (project no. 18-013-00094). 


\section{For citation}

Shamionov R. M., Sultaniyazova N. Zh. Values and Attitudes to Ethnic Culture and Traditions as Predictors of Subjective Well-Being Among Russians and Kazakhs. Rossiiskii psikhologicheskii zhurnal - Russian Psychological Journal, 2018, V. 15, no. 1, pp. 157-186 (in Russian). DOI: 10.21702/rpj.2018.1.8

Original manuscript received 25.01.2017

\section{Введение}

Проблема детерминации субъективного благополучия личности относится к числу наиболее актуальных в связи с динамикой социально-политических, экономических, научно-производственных изменений во всем мире. Все они концентрируются вокруг понятий «глобализация», «мультикультурализм», «миграция». Иначе говоря, изменения в жизни современных поколений во многом предопределены новыми возможностями и поиском условий наилучшего существования и самореализации. Поэтому поиск детерминант субъективного благополучия теснейшим образом связан с возможностями создания условий для его формирования или поддержания. Исследователи подчеркивают психосоциальный характер понятия субъективного благополучия, поскольку оно может быть отнесено и к индивиду, и к группе, и к обществу в целом, но на разных уровнях анализа приобретает разное наполнение [1]. Это задает определенный вектор в исследовании субъективного благополучия как явления многоуровневого и поэтому порождаемого в результате совместной детерминации ряда инстанций личности/группы/общества. Отметим, что такой ракурс проблемы еще находится на ранних этапах разработки.

Между тем, в результате анализа представлений о счастье в фольклорном и обыденном сознании россиян Л.Е. Тарасова обнаружила, что и в том и в другом «...лидируют представления о счастье как об отсутствии физических и моральных страданий, несчастий и душевный покой» [2, с. 67]. Иначе говоря, этнокультурные установки имеют большое значение для вынесения суждения о собственном благополучии, но вряд ли прямо влияют на оценку удовлетворенности повседневной жизненной ситуацией, т. к. проявляются одинаково. С другой стороны, И.А. Джидарьян выявила наличие этнической специфики переживания счастья (на примере русских), которая заключается в традиционных для этнической группы переживаниях «меры» счастья и «доброжелательной тональности при восприятии несчастья» [3, с. 40].

Многочисленные исследования детерминант благополучия, проведенные за последние десятилетия, позволили выявить значение различных характеристик личности и среды, обусловливающих переживания субъективного благополучия. Они же в значительной степени продвинули исследователей 


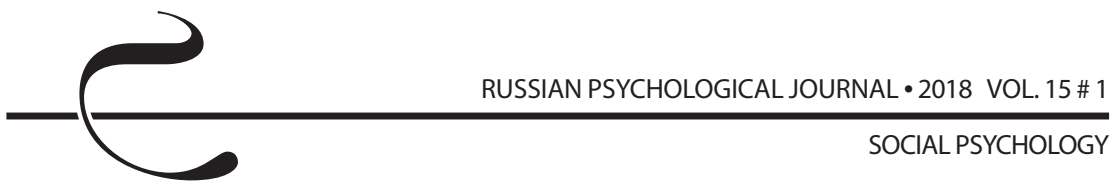

в решении проблемы дифференциации детерминант. В частности, К.M. Sheldon произведена дифференциация функциональных уровней детерминант - социальных, культурных, личностных и др., влияющих на поведение и опыт человека, в том числе и субъективное благополучие $[4,5]$.

Ранее мы отмечали, что соответствие поведения «культурному предназначению» приводит к более высоким показателям благополучия [6]. Вместе с тем, в условиях смешения культур, все более сильной автономизации личности происходит значительный уход от традиционных (этнических и даже национальных) ценностей и культурных феноменов, и обращение к универсальным, надэтническим и наднациональным, что создает, говоря словами А. В. Сухарева, «функциональную дисгармонию» - нарушения этнофункционального развития личности - характеризующиеся «рассогласованием образного и др. содержания стадий этнофункционального развития личности с архегенией этносреды ее рождения» [7, с. 116]. Иначе говоря, рассогласование этнических традиционных ценностей с реализуемым поведением в широком спектре его проявлений приводит к дезадаптации личности и различным дисгармониям. В то же время, исследователи отмечают, что изменение значимости культурных ценностей можно рассматривать как социально-психологический критерий влияния макросоциальных изменений на ценностное сознание личности [8]. С другой стороны, М. Чиксентмихайи отмечает, что защитные механизмы, которые несут в себе религия, патриотизм, народные традиции и общественные нормы, оказываются неэффективными и не способствующими адаптации в настоящее время. Одним из наиболее эффективных путей в достижении внутреннего равновесия он считает «независимость от социального окружения, путь автономизации для развития способности испытывать радость независимо от внешних обстоятельств» [9, с. 42-34]. Однако речь не идет об отвержении всех общественных целей, но о выстраивании собственной системы целей, которая будет способна дополнить или заменить социальные. Тем не менее, исследование R.J. Taormina, R.M. Shamionov [10], проведенное одновременно в Китае и России, позволило выяснить, что следование традиционным ценностям одинаково способствует переживанию удовлетворенности жизнью в разных культурах.

Весьма интересные исследования, проведенные Н.М. Лебедевой $[11,12]$ убедительно доказывают, что существуют межкультурные и межполовые различия в индивидуальных ценностях представителей изученных этнических групп. Эти исследования примечательны тем, что они проливают свет на ценностные детерминанты отношения к инновациям. Во втором исследовании отмечаются также взаимосвязи ценностей с характеристиками субъективного благополучия личности. 
На протяжении более 20 лет нами и нашими коллегами проводились исследования ценностных детерминант субъективного благополучия. В наших исследованиях были выявлены значимые ценности как факторы субъективного эмоционального благополучия. В частности, изучая три этнические группы, мы обнаружили, что у русских субъективное благополучие связано с групповыми ценностями, характеризующими субъектно-коллективистскую ориентацию (миролюбие, верность традициям, дисциплинированность, самостоятельность); у представителей казахского этноса - субъектно-групповую (взаимовыручка, уступчивость, уважение власти, самостоятельность); у армян-мигрантов - субъектно-независимую (открытость, своеволие, взаимовыручка, осторожность) [13]. В других исследованиях нами было установлено, что психологическое благополучие русских обусловливается культурной характеристикой «горизонтальный индивидуализм», у казахов - «горизонтальным коллективизмом». Групповые ценности русских оказывают в значительной степени меньшее воздействие на компоненты психологического благополучия, чем ценности казахов [14]. Позже удалось обнаружить, что одни и те же характеристики личности - будь то уверенность в себе или убеждения - имеют разный вес в их влиянии на ту или иную сторону (эмоциональную или психологическую) субъективного благополучия личности в зависимости от условий этнокультурной социализации личности [15]. Близкие к этим выводы были сделаны и в исследовании зарубежных коллег, в которых установлено, что стойкие убеждения, верования обусловливают вариации субъективного благополучия [16 и др.] Ценностные детерминанты субъективного благополучия в этнопсихологическом или кросскультурном аспекте анализировались рядом исследователей за рубежом, преимущественно применительно к мигрантам [17, 18, 19, 20, 21, 22]. Из результатов этих исследований следует, что ценностные детерминанты субъективного благополучия соотносятся либо с культурными универсалиями, либо сложившимися национальными (общественными) представлениями о наиболее эффективных способах адаптации, включая и политические предпочтения.

Таким образом, ценности, являясь продуктом социального творчества многих поколений этнических групп, обусловливают не только характер приспособления, но и вариации субъективного благополучия личности, что, скорее, происходит опосредованно, через соответствие ценностей и реализуемой активности.

Исследований соотношения субъективного благополучия и приверженности этнической культуре, отношения к традициям и культуре своего и других народов значительно меньше ввиду распространенных формализованных опросников на эту тему. Тем не менее, в ряде исследований этот вопрос затрагивался. В частности, в исследовании В.В. Гриценко было показано, что 


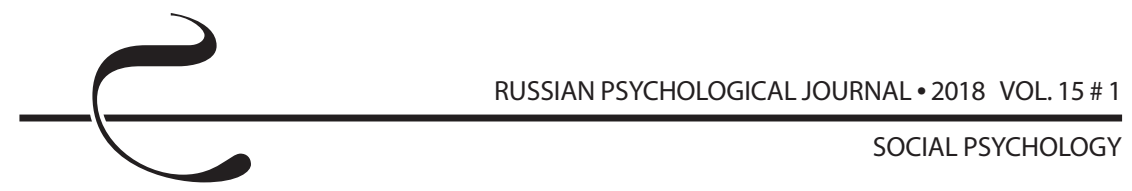

позитивный автостереотип и позитивный гетеростереотип способствуют более успешной адаптации мигрантов. Небезынтересны также данные, согласно которым установки переселенцев на сохранение прежних культурных заимствований, особенно на начальных этапах, способствуют уменьшению стресса аккультурации [23]. Эти данные свидетельствуют о позитивной связи между отношением к Другим и ситуативным благополучием личности. В исследованиях E. Diner и его коллег были обнаружены взаимосвязи между показателями субъективного благополучия (удовлетворенностью жизнью, балансом аффекта) и культурными ориентациями, этнической идентичностью, отношением к традициям $[24,25]$. Позже в исследовании Р. М. Шамионова было показано, что сила этнических чувств (гордость, радость, единение со своим народом) сопряжена с удовлетворенностью отношениями с коллегами $\left(0,207^{*}\right)$, удовлетворенностью своим характером $\left(0,178^{*}\right)$, уверенностью в себе $\left(0,236^{* *}\right)$, т. е. со спектром позитивных отношений с собой и Другими. Однако в то же время было показано, что гражданская идентичность является более значимым, чем приверженность к этнической группе и сила религиозных чувств, предиктором характеристик субъективного благополучия [26]. Но эти разрозненные данные не позволяют с полной уверенностью говорить о соответствующей детерминации, и требуются исследования для выяснения вопроса об «уровне вклада» в субъективное благополучие характеристик отношения представителей этнических групп и наций к вариациям субъективного благополучия. Поэтому цель настоящего исследования заключается в анализе ценностей и отношения к этнической культуре и традициям как предикторов субъективного благополучия русских и казахов, проживающих в России и Казахстане.

\section{Методы}

\section{Выборка}

Исследование проводилось на пропорционально подобранных выборках представителей двух этнических групп России и Казахстана - по 75 человек; всего в исследовании приняло участие 300 человек обоего пола (29\% мужчин), средний возраст 38 лет, SD =11,57, 69\% горожан, $31 \%$ сельчан.

Для измерения трех характеристик субъективного благополучия были использованы следующие методики: «Шкала удовлетворенности жизнью» Э. Динера в адаптации Д.А. Леонтьева, Е.Н. Осина [27], включающая пять утверждений, оцениваемых по семибалльной шкале; «Шкала субъективного счастья» С. Любомирски и Х. Леппер в адаптации Д. А. Леонтьева, Е.Н. Осина [27] (вариант шкалы из 4-х утверждений, оцениваемых по семибалльной шкале). Параметры психологического благополучия (автономность, компетентность, личностный рост, жизненные цели, самопринятие, общий 
показатель) замерялись с помощью шкалы К. Рифф в адаптации Л.В. Жуковской и Е.Г. Трошихиной (полный вариант) [28]. Выраженность ценностей определена с помощью методики С. Шварца. В соответствии с методикой определяется выраженность 19-ти ценностей, которые располагаются на континууме: смежные ценности являются наиболее совместимыми, а противоположные находятся в наибольшем конфликте друг с другом [29, 30].

Для анализа отношений представителей этнических групп к этнической культуре и традициям были разработаны психологические шкалы, предусматривающие 5 вариантов ответов - от абсолютного несогласия (1) до абсолютного согласия (5). Шкалы были предъявлены пяти экспертам - специалистам в области этнологии и этнической психологии - для оценки их соответствия изучаемому феномену. После чего были отбракованы 7 шкал и оставлены 24 шкалы.

\section{Методы обработки}

Для обработки первичных данных использовалась статистическая программа Statistical Package for the Social Sciences (SPSS 19.0). Для определения внутренней согласованности психологических шкал вычислялся коэффициент альфа Кронбаха. Использованы параметрический метод сравнения выборок (t-критерий Стьюдента), корреляционный и регрессионный анализы.

\section{Результаты}

Обратимся к результатам сравнительного анализа выраженности ценностей в различных группах (авторы готовы предоставить все данные по компаративному и корреляционному анализам; можно обратиться по адресу: shamionov@sgu.ru.-nрuм.P.Ш.).

PP - PK: различия выраженности ценностей связаны, главным образом, с ценностями «самостоятельность: мысли» $(\mathrm{t}=3,71 ; \mathrm{p}<0,01)$, «межличностный конформизм» $(\mathrm{t}=2,04 ; \mathrm{p}<0,05)$ и «универсализм: забота о других» $(\mathrm{t}=2,23$; $\mathrm{p}<0,05)$ - более выражены у российских русских, чем казахов. Культурные универсалии схожи.

PP - KP: сравнение двух выборок русских, проживающих на исторической родине и вне ее дает ценный материал относительно не только абсолютных значений, но и того, имеются ли какие-либо заимствования у последних. Ценность «самостоятельность: поступки» $(\mathrm{t}=2,59 ; \mathrm{p}<0,01)$ и «власть: доминирование» $(\mathrm{t}=2,46 ; \mathrm{p}<0,01)$ более выражены у русских Казахстана, а толерантность более выражена у русских в России ( $t=1,99 ; \mathrm{p}<0,05)$. Горизонтальный коллективизм ( $\mathrm{t}=1,99 ; \mathrm{p}<0,05)$ и вертикальный коллективизм $(\mathrm{t}=2,78$, $\mathrm{p}<0,01$ ) (данные показатели выявлены с помощью шкалы воспринимаемого культурного контекста В.И. Чиркова) более выражены у российских русских. 


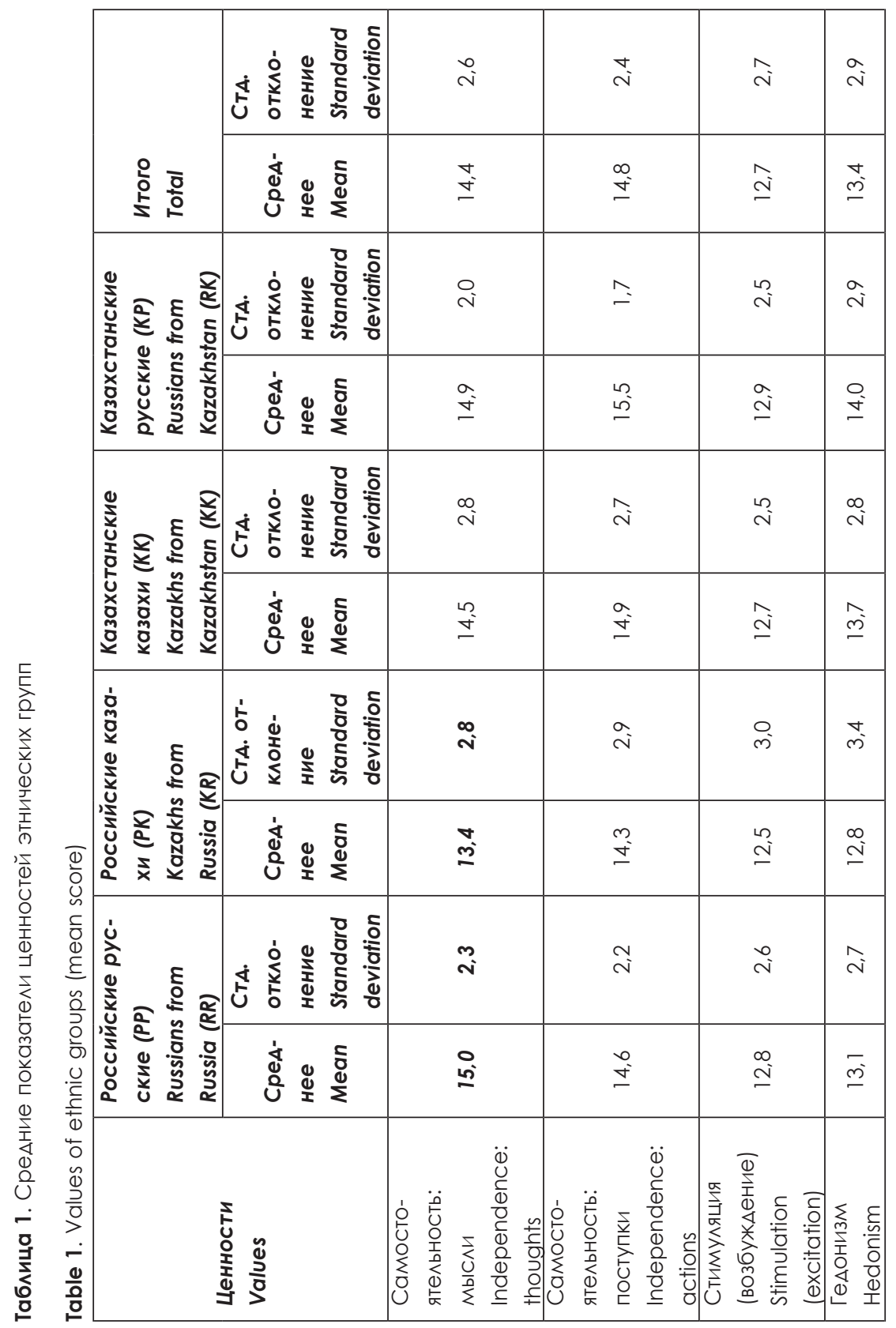




\begin{tabular}{|c|c|c|c|c|c|c|}
\hline \multirow[b]{2}{*}{$\begin{array}{l}\circ \\
\stackrel{0}{\circ} \overline{0} \\
\stackrel{5}{5}\end{array}$} & 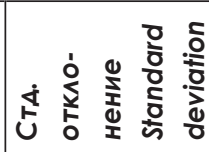 & $\stackrel{a}{i}$ & $\stackrel{n}{\infty}$ & $\stackrel{n}{m}$ & $\stackrel{a}{\sim}$ & $\stackrel{\infty}{\sim}$ \\
\hline & 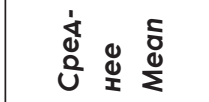 & $\overline{\underline{m}}$ & $\stackrel{\circ}{\circ}$ & $\stackrel{+}{\circ}$ & $\stackrel{\sim}{\underset{ \pm}{ \pm}}$ & $\begin{array}{l}\circ \\
\underset{ \pm}{ \pm}\end{array}$ \\
\hline \multirow{2}{*}{ 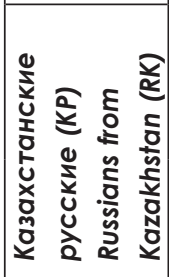 } & 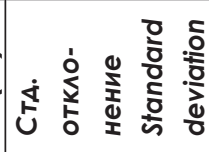 & $\stackrel{\infty}{\sim}$ & $\stackrel{\circ}{m}$ & $\hat{m}$ & $\stackrel{\infty}{i}$ & $\stackrel{n}{\sim}$ \\
\hline & 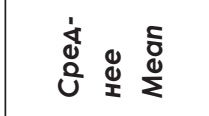 & $\overline{\underline{m}}$ & $\stackrel{+}{\circ}$ & $\begin{array}{l}\forall \\
\stackrel{0}{0}\end{array}$ & $\underset{⿱}{ \pm}$ & $\begin{array}{l}\infty \\
\underset{ \pm}{ \pm}\end{array}$ \\
\hline \multirow{2}{*}{ 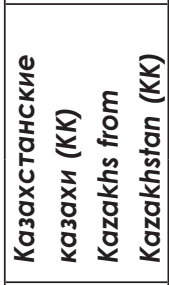 } & 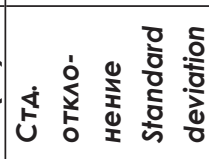 & 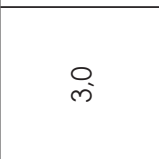 & $\bar{m}$ & $\stackrel{n}{m}$ & $\hat{\mathrm{i}}$ & $\stackrel{\circ}{i}$ \\
\hline & 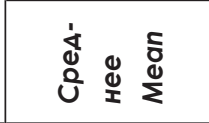 & $\hat{\underline{m}}$ & $\stackrel{\forall}{\circ}$ & $\stackrel{m}{=}$ & $\begin{array}{l}\stackrel{n}{ \pm} \\
\stackrel{\sim}{ \pm}\end{array}$ & $\bar{L}$ \\
\hline \multirow{2}{*}{ 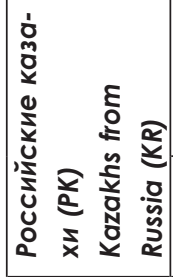 } & 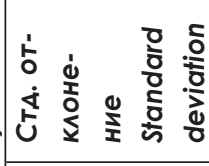 & $\bar{m}$ & $\hat{m}$ & $\stackrel{m}{m}$ & $\stackrel{+}{m}$ & $\stackrel{N}{m}$ \\
\hline & 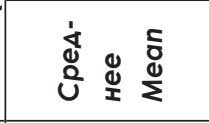 & $\widehat{\cong}$ & $\overline{0}$ & $\stackrel{+}{\circ}$ & $\stackrel{\infty}{\stackrel{\infty}{m}}$ & 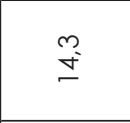 \\
\hline \multirow{2}{*}{ 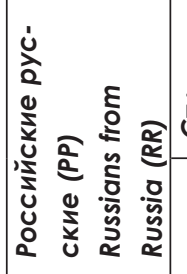 } & 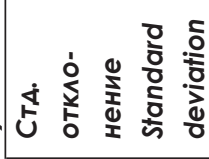 & $\bar{m}$ & $\stackrel{\varpi}{\ddot{m}}$ & $\stackrel{+}{m}$ & $\stackrel{\circ}{\sim}$ & $\stackrel{\circ}{\sim}$ \\
\hline & 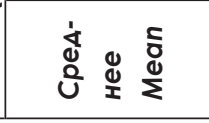 & $\stackrel{\infty}{\stackrel{\infty}{\subseteq}}$ & $\stackrel{\circ}{\circ}$ & $a^{\circ}$ & $\bar{\Xi}$ & $\underset{⿱}{ \pm}$ \\
\hline \multicolumn{2}{|c|}{ 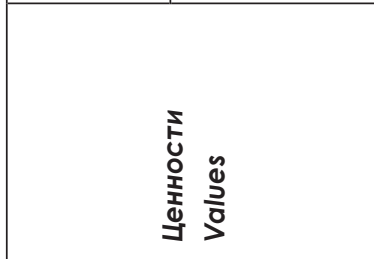 } & 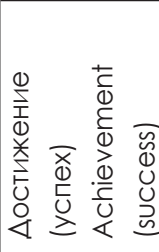 & 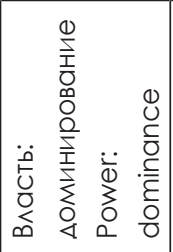 & 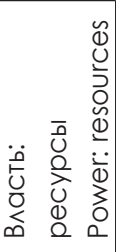 & 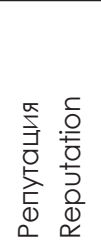 & 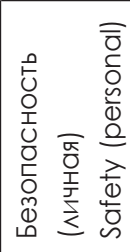 \\
\hline
\end{tabular}




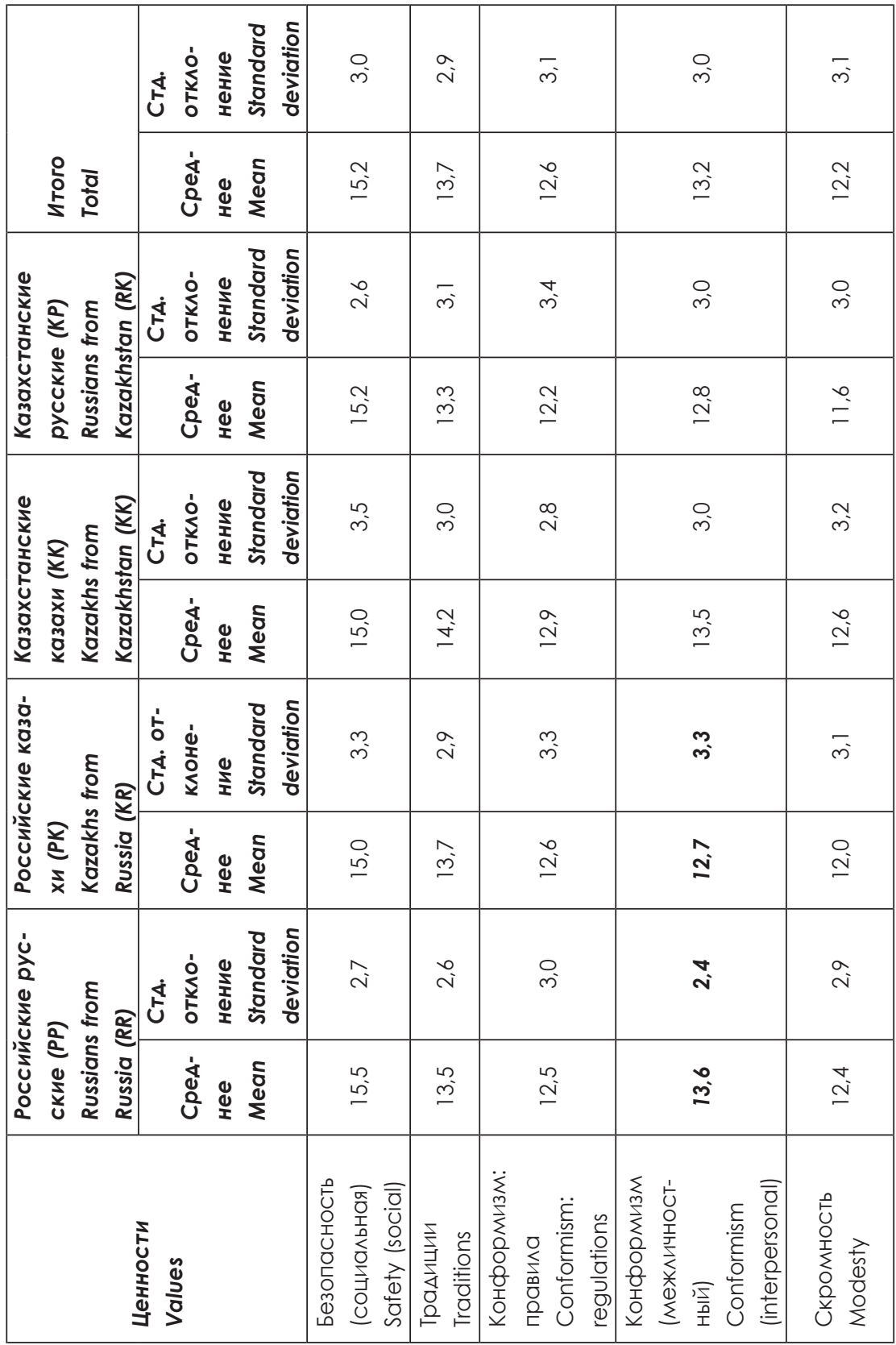




\begin{tabular}{|c|c|c|c|c|c|c|}
\hline & 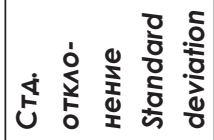 & $\bar{m}$ & $\hat{\mathrm{i}}$ & $\stackrel{\curvearrowright}{\sim}$ & $\stackrel{\circ}{\sim}$ & $\hat{\mathrm{N}}$ \\
\hline 옹 흔 & 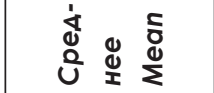 & $\hat{\bar{m}}$ & $\underset{ \pm}{\stackrel{ \pm}{ \pm}}$ & $\stackrel{m}{\underline{m}}$ & $\stackrel{\sim}{\sim}$ & $\begin{array}{l}\stackrel{\sigma}{ \pm} \\
\text { D }\end{array}$ \\
\hline 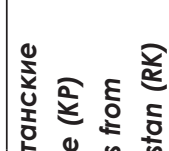 & 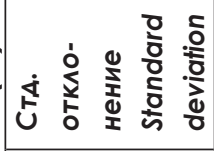 & $\stackrel{\circ}{\text { ले }}$ & $\hat{\sim}$ & $\hat{i}$ & $\stackrel{m}{\sim}$ & $\stackrel{\circ}{\text { N }}$ \\
\hline 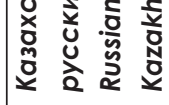 & 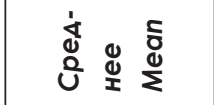 & $\stackrel{\sim}{m}$ & $\stackrel{\mathscr{n}}{\mathbb{J}}$ & $\stackrel{\circ}{\text { mे }}$ & ָூ & $\begin{array}{c}\text { ma } \\
\text { Lే }\end{array}$ \\
\hline 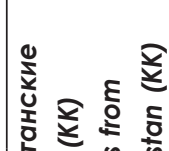 & 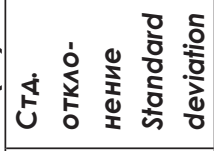 & $\stackrel{N}{n}$ & $\stackrel{m}{m}$ & ભ̀ & $\stackrel{0}{\sim}$ & $\stackrel{\circ}{\text { ले }}$ \\
\hline 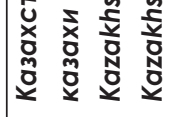 & 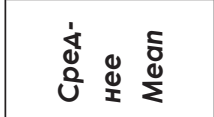 & 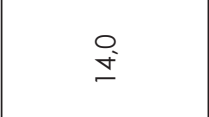 & $\underset{⿱}{ \pm}$ & $\stackrel{m}{m}$ & 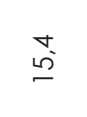 & $\underset{\sim}{\stackrel{a}{+}}$ \\
\hline 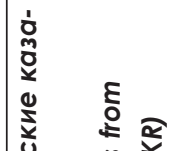 & 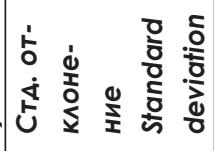 & $\stackrel{m}{m}$ & ָૈ & $\stackrel{N}{m}$ & $\bar{m}$ & $\stackrel{N}{m}$ \\
\hline 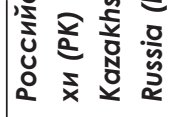 & 过 & $\begin{array}{l}\tilde{n} \\
\dot{D}\end{array}$ & $\stackrel{\alpha}{\underline{m}}$ & $\bar{m}$ & E) & 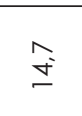 \\
\hline 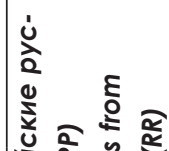 & 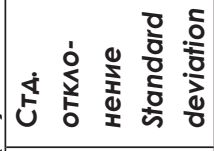 & $\hat{\mathrm{N}}$ & $\tilde{N}$ & $\stackrel{+}{i}$ & $\stackrel{m}{N}$ & $\stackrel{\circ}{\sim}$ \\
\hline 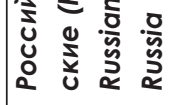 & 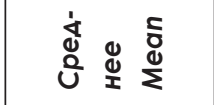 & $\hat{\underline{m}}$ & $\underset{\sim}{\mathbb{\Xi}}$ & 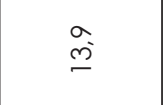 & $\overline{5}$ & $\begin{array}{l}\infty \\
\underset{ \pm}{ \pm}\end{array}$ \\
\hline & 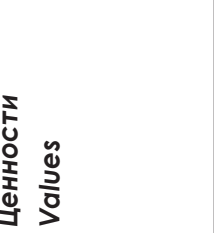 & 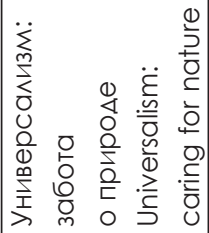 & 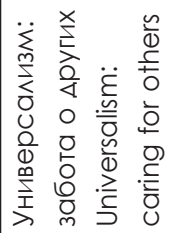 & 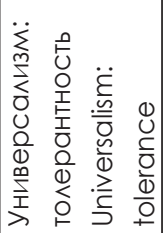 & 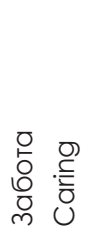 & 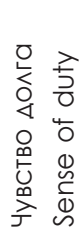 \\
\hline
\end{tabular}




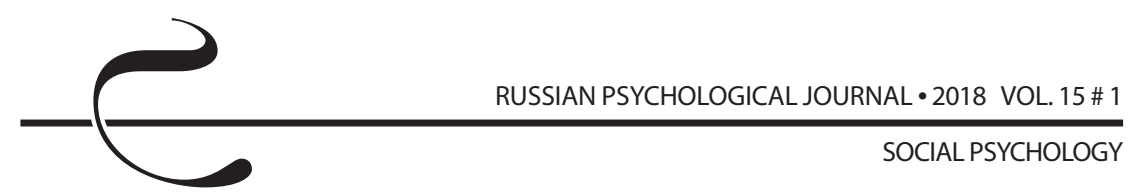

$\boldsymbol{P P}$ - KK: сравнение двух титульных этнических групп позволило выявить различия двух ценностей - «власть: ресурсы» $(\mathrm{t}=3,12 ; \mathrm{p}<0,01)$ и «власть: доминирование» $(\mathrm{t}=2,56 ; \mathrm{p}<0,01)$ более значимы для казахов.

$P K$ - KK: ценности достижения успеха $(\mathrm{t}=1,98 ; \mathrm{p}<0,05)$ и самостоятельности мысли $(t=2,35 ; p<0,05)$ более выражены у титульной нации Казахстана, в отличие от российских казахов. Культурные универсалии схожи.

PK - KР: ряд ценностей, более значимый для русских в Казахстане - самостоятельность мыслей $(t=3,78 ; p<0,01)$, самостоятельность поступков $(t=3,12 ; p<0,01)$, гедонизм $(t=2,35 ; p<0,05)-$ и менее значимый для казахов в России. Горизонтальный коллективизм $(\mathrm{t}=2,68 ; \mathrm{p}<0,01)$ и вертикальный коллективизм $(t=2,08 ; \mathrm{p}<0,05)$ более выражены у российских казахов и менее выражены у русских в Казахстане.

KК - KР: в Казахстане выявлены наименьшие различия. Так, более выражены у казахов ценность «скромность» $(\mathrm{t}=2,08 ; \mathrm{p}<0,05)$ и культурная ориентация «вертикальный коллективизм» $(\mathrm{t}=2,41 ; \mathrm{p}<0,05)$.

Как видно из таблицы 2, наиболее разнородна ценностная детерминация удовлетворенности жизнью. Поскольку эта характеристика субъективного благополучия наиболее «близка» к ежедневным событиям и ситуациям, очевидно в разных условиях ее обусловливают важные для приспособления к ним ценности как задающие направленность личности образования. Для русских россиян это чувство долга, характеризуемое стремлением быть надежным членом группы, казахов-россиян - ценность достижений успеха в соответствии с социальными стандартами, а для казахов Казахстана - конформизм как стремление избежать причинения вреда или огорчения Другим. Имеются также различия в детерминации психологического благополучия, заключающиеся в числе переменных, включенных в регрессионное уравнение. Так, у русских россиян это одна переменная - «самостоятельность поступков», у казахов-россиян - две переменные - «самостоятельность: мысли» и «скромность» (выражены отрицательно); у казахов Казахстана - «самостоятельность: мысли» и «власть: доминирование» (отрицательно) и русских Казахстана - «самостоятельность: мысли», «традиции» (положительно), «скромность», «универсализм», «власть: ресурсы» (отрицательно). Из этих данных видно, что выраженность ряда ценностей подрывает психологическое благополучие: в выборках этнических меньшинств - это скромность (как признание незначительности существования одного человека в круговороте жизни), в выборках Казахстана - это власть (влияние посредством контроля над людьми - у казахов, влияние посредством контроля ресурсов - у русских) и сохранение природной среды (казахстанские русские).

Обратимся к результатам регрессионного анализа, в котором показатели субъективного благополучия являются зависимыми переменными, а характеристики отношения к культуре и традициям народов - независимыми (таблица 3). 
Таблица 2. Ценностные предикторы характеристик субъективного благополучия

Table 2. Value predictors of subjective well-being

\begin{tabular}{|c|c|c|c|c|c|c|c|c|}
\hline \multirow{3}{*}{$\begin{array}{c}\text { Предикторы } \\
\text { удовлетво- } \\
\text { ренности } \\
\text { жизнью } \\
\text { Life } \\
\text { satisfaction } \\
\text { predictors }\end{array}$} & \multicolumn{4}{|c|}{$\begin{array}{c}\text { Россия } \\
\text { Russia }\end{array}$} & \multicolumn{4}{|c|}{$\begin{array}{l}\text { Казахстан } \\
\text { Kazakhstan }\end{array}$} \\
\hline & \multicolumn{2}{|c|}{$\begin{array}{l}\text { Русские } \\
\text { Russians }\end{array}$} & \multicolumn{2}{|c|}{$\begin{array}{l}\text { Казахи } \\
\text { Kazakhs }\end{array}$} & \multicolumn{2}{|c|}{$\begin{array}{l}\text { Казахи } \\
\text { Kazakhs }\end{array}$} & \multicolumn{2}{|c|}{$\begin{array}{l}\text { Русские } \\
\text { Russians }\end{array}$} \\
\hline & $\Delta R$ & $\beta$ & $\Delta R$ & $\beta$ & $\Delta R$ & $\beta$ & $\Delta R$ & $\beta$ \\
\hline $\begin{array}{l}\text { Чувство Аолга } \\
\text { Sense of duty }\end{array}$ & 0,16 & $0,402^{* * * *}$ & - & - & - & - & - & - \\
\hline $\begin{array}{l}\text { Аостижение } \\
\text { Achievement }\end{array}$ & - & - & 0,09 & $0,301^{* *}$ & - & - & - & - \\
\hline $\begin{array}{l}\text { Конфрормизм } \\
\text { (межличност- } \\
\text { ный) } \\
\text { Conformism } \\
\text { (interpersonal) }\end{array}$ & - & - & - & - & 0,11 & $0,335^{* *}$ & - & - \\
\hline & \multicolumn{2}{|c|}{$\begin{array}{l}R^{2}=0,16 \\
F=16,05 \\
p<0,001\end{array}$} & \multicolumn{2}{|c|}{$\begin{array}{l}R^{2}=0,09 ; \\
F=7,26 ; \\
p<0,01\end{array}$} & \multicolumn{2}{|c|}{$\begin{array}{l}R^{2}=0,11 \\
F=9,08 \\
p<0,01\end{array}$} & \multicolumn{2}{|c|}{-} \\
\hline $\begin{array}{l}\text { Предикторы } \\
\text { счастья } \\
\text { Predictors of } \\
\text { happiness }\end{array}$ & $\Delta R$ & $\beta$ & $\Delta R$ & $\beta$ & $\Delta R$ & $\beta$ & $\Delta R$ & $\beta$ \\
\hline $\begin{array}{l}\text { Самостоя- } \\
\text { тельность: } \\
\text { мысли } \\
\text { Indepen- } \\
\text { dence: } \\
\text { thoughts }\end{array}$ & 0,15 & $0,289^{* *}$ & 0,07 & $0,271^{*}$ & 0,10 & $0,616^{* *}$ & - & - \\
\hline
\end{tabular}




\begin{tabular}{|c|c|c|c|c|c|c|c|c|}
\hline $\begin{array}{l}\text { Самостоя- } \\
\text { тельность: } \\
\text { поступки } \\
\text { Indepen- } \\
\text { dence: } \\
\text { actions } \\
\end{array}$ & - & - & - & - & 0,06 & $-0,393^{*}$ & - & - \\
\hline $\begin{array}{l}\text { ГеАОнизм } \\
\text { Hedonism }\end{array}$ & 0,05 & $0,250^{*}$ & - & - & - & - & - & - \\
\hline & \multicolumn{2}{|c|}{$\begin{array}{l}\mathrm{R}^{2}=0,20 ; \\
\mathrm{F}=8,95 ; \\
\mathrm{P}<0,001\end{array}$} & \multicolumn{2}{|c|}{$\begin{array}{l}\mathrm{R}^{2}=0,07 \\
\mathrm{~F}=5,77 \\
\mathrm{p}<0,05\end{array}$} & \multicolumn{2}{|c|}{$\begin{array}{l}R^{2}=0,16 \\
F=6,63 \\
p<0,01\end{array}$} & \multicolumn{2}{|c|}{-} \\
\hline $\begin{array}{l}\text { Предикторы } \\
\text { психоло- } \\
\text { гического } \\
\text { благополучия } \\
\text { Predictors of } \\
\text { psychological } \\
\text { well-being }\end{array}$ & $\Delta R$ & $\beta$ & $\Delta R$ & $\beta$ & $\Delta R$ & $\beta$ & $\Delta R$ & $\beta$ \\
\hline $\begin{array}{l}\text { Самостоя- } \\
\text { тельность: } \\
\text { мысли } \\
\text { Indepen- } \\
\text { dence: } \\
\text { thoughts }\end{array}$ & - & - & 0,13 & $0,514^{* * *}$ & 0,13 & $0,391^{* *}$ & 0,07 & $0,323^{* *}$ \\
\hline $\begin{array}{l}\text { Самостоя- } \\
\text { тельность: } \\
\text { поступки } \\
\text { Indepen- } \\
\text { dence: } \\
\text { actions }\end{array}$ & 0,31 & $0,558^{* * *}$ & - & - & - & - & - & - \\
\hline $\begin{array}{l}\text { Скромность } \\
\text { Modesty }\end{array}$ & - & - & 0,09 & $-0,329 * *$ & - & - & 0,07 & $-0,301^{*}$ \\
\hline
\end{tabular}


СОЦИАЛЬНАЯ ПСИХОЛОГИЯ

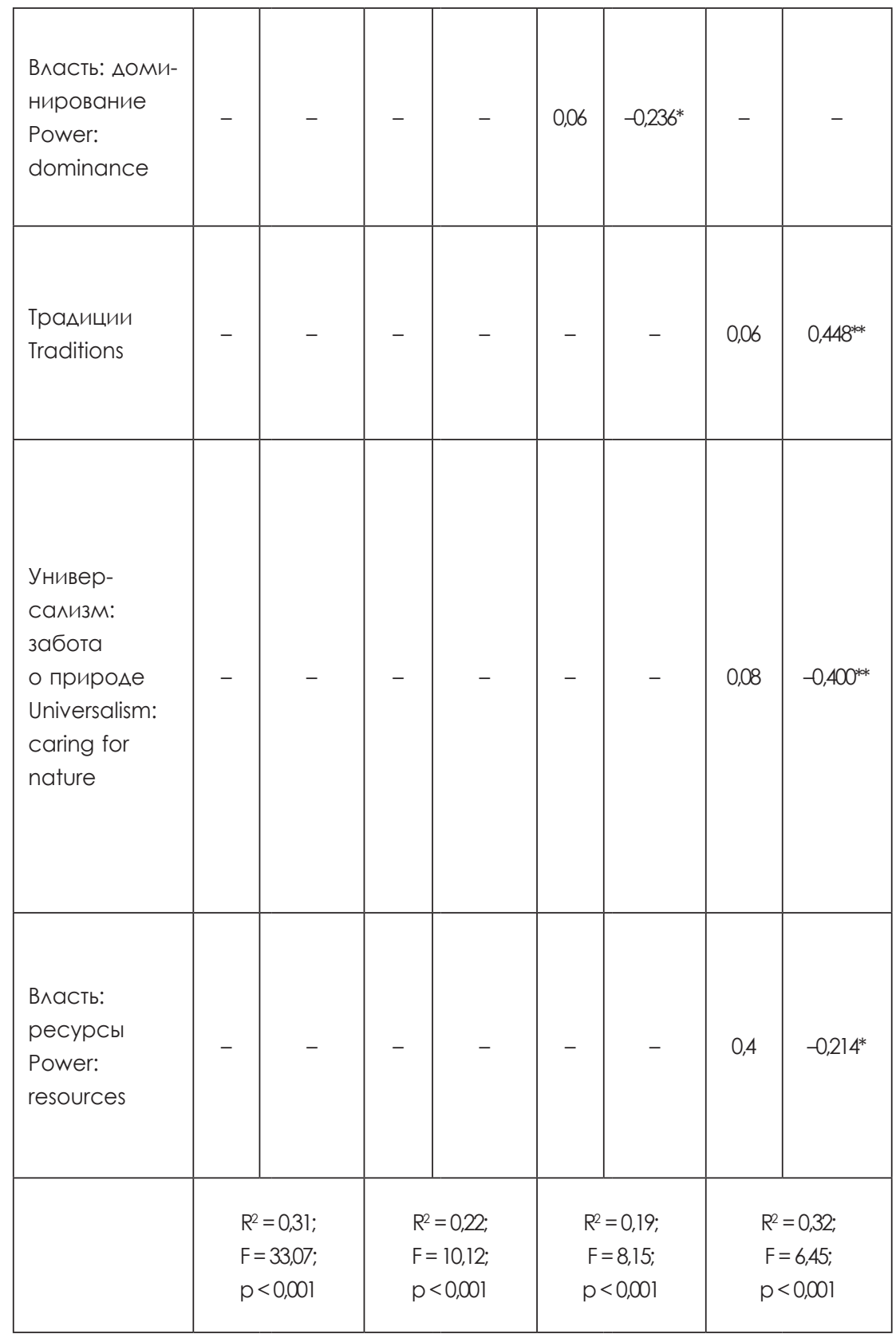


Таблица 3. Отношение к культуре как предиктор характеристик субъективного благополучия

Table 3. Attitudes to culture as predictors of subjective well-being

\begin{tabular}{|c|c|c|c|c|c|c|c|c|}
\hline \multirow{3}{*}{$\begin{array}{c}\text { Предикторы } \\
\text { уАовлетво- } \\
\text { ренности } \\
\text { жизнью } \\
\text { Life } \\
\text { satisfaction } \\
\text { predictors }\end{array}$} & \multicolumn{4}{|c|}{$\begin{array}{l}\text { Россия } \\
\text { Russia }\end{array}$} & \multicolumn{4}{|c|}{$\begin{array}{l}\text { Казахстан } \\
\text { Kazakhstan }\end{array}$} \\
\hline & \multicolumn{2}{|c|}{$\begin{array}{l}\text { Русские } \\
\text { Russians }\end{array}$} & \multicolumn{2}{|c|}{$\begin{array}{l}\text { Казахи } \\
\text { Kazakhs }\end{array}$} & \multicolumn{2}{|c|}{$\begin{array}{l}\text { Казахи } \\
\text { Kazakhs }\end{array}$} & \multicolumn{2}{|c|}{$\begin{array}{l}\text { Русские } \\
\text { Russians }\end{array}$} \\
\hline & $\Delta R$ & $\beta$ & $\Delta R$ & $\beta$ & $\Delta R$ & $\beta$ & $\Delta R$ & $\beta$ \\
\hline $\begin{array}{l}\text { ВкАюченность } \\
\text { в культуру } \\
\text { и тради- } \\
\text { ции своего } \\
\text { народа } \\
\text { Involvement } \\
\text { in their own } \\
\text { people's } \\
\text { culture and } \\
\text { traditions }\end{array}$ & 0,08 & $0,361^{* *}$ & - & - & 0,06 & $0,25^{*}$ & - & - \\
\hline $\begin{array}{l}\text { Интерес к } \\
\text { культуре Ару- } \\
\text { гих народов } \\
\text { Interest in oth- } \\
\text { er cultures }\end{array}$ & 0,07 & $-0,24^{*}$ & - & - & - & - & - & - \\
\hline & \multicolumn{2}{|c|}{$\begin{array}{l}\mathrm{R}^{2}=0,15 ; \\
\mathrm{F}=5,71 ; \\
\mathrm{p}<0,005\end{array}$} & \multicolumn{2}{|c|}{-} & \multicolumn{2}{|c|}{$\begin{array}{l}\mathrm{R}^{2}=0,06 \\
\mathrm{~F}=4,81 \\
\mathrm{p}<0,05\end{array}$} & \multicolumn{2}{|c|}{-} \\
\hline $\begin{array}{l}\text { ПреАикторы } \\
\text { счастья } \\
\text { Predictors of } \\
\text { happiness }\end{array}$ & $\Delta R$ & $\beta$ & $\Delta R$ & $\beta$ & $\Delta R$ & $\beta$ & $\Delta R$ & $\beta$ \\
\hline $\begin{array}{l}\text { Культура как } \\
\text { основа еАин- } \\
\text { ства народа } \\
\text { Culture as the } \\
\text { basis of the } \\
\text { unity of the } \\
\text { people }\end{array}$ & 0,10 & $0,321^{* *}$ & - & - & 0,19 & $0,264^{*}$ & - & - \\
\hline
\end{tabular}




\begin{tabular}{|c|c|c|c|c|c|c|c|c|}
\hline $\begin{array}{l}\text { Позитивное } \\
\text { отношение } \\
\text { к замеще- } \\
\text { нию тради- } \\
\text { ционных цен- } \\
\text { ностей ев- } \\
\text { ропейскими } \\
\text { ценностями } \\
\text { Positive at- } \\
\text { titude to the } \\
\text { replacement } \\
\text { of traditional } \\
\text { values with } \\
\text { European } \\
\text { ones }\end{array}$ & - & - & 0,05 & $0,233^{*}$ & - & - & - & - \\
\hline $\begin{array}{l}\text { Праздно- } \\
\text { вание зна- } \\
\text { менательных } \\
\text { Аат Аругих } \\
\text { народов } \\
\text { Celebrating } \\
\text { the dates } \\
\text { significant for } \\
\text { other peoples }\end{array}$ & - & - & - & - & 0,06 & $0,343^{* *}$ & - & - \\
\hline $\begin{array}{l}\text { Интерес к } \\
\text { культуре Ару- } \\
\text { гих народов } \\
\text { Interest in oth- } \\
\text { er cultures }\end{array}$ & - & - & - & - & 0,13 & $-0,423^{* *}$ & - & - \\
\hline $\begin{array}{l}\text { Соблюление } \\
\text { традиций и } \\
\text { обычаев сво- } \\
\text { его народа } \\
\text { Observance } \\
\text { of their own } \\
\text { people's tra- } \\
\text { ditions and } \\
\text { customs }\end{array}$ & - & - & - & - & - & - & 0,07 & $0,263^{*}$ \\
\hline
\end{tabular}




\begin{tabular}{|c|c|c|c|c|c|c|c|c|}
\hline & \multicolumn{2}{|c|}{$\begin{array}{c}R^{2}=0,10 \\
F=8,36 \\
P<0,005\end{array}$} & \multicolumn{2}{|c|}{$\begin{array}{l}R^{2}=0,05 \\
F=4,20 \\
P<0,05\end{array}$} & \multicolumn{2}{|c|}{$\begin{array}{c}\mathrm{R}^{2}=0,19 \\
\mathrm{~F}=5,42 \\
\mathrm{p}<0,002\end{array}$} & \multicolumn{2}{|c|}{$\begin{array}{c}\mathrm{R}^{2}=0,07 \\
\mathrm{~F}=5,42 \\
\mathrm{p}<0,02\end{array}$} \\
\hline $\begin{array}{l}\text { Предикторы } \\
\text { психоло- } \\
\text { гического } \\
\text { благополучия } \\
\text { Predictors of } \\
\text { psychological } \\
\text { well-being }\end{array}$ & $\Delta R$ & $\beta$ & $\Delta R$ & $\beta$ & $\Delta R$ & $\beta$ & $\Delta R$ & $\beta$ \\
\hline $\begin{array}{l}\text { Следование } \\
\text { традицион- } \\
\text { ным ценно- } \\
\text { стям народа } \\
\text { Following their } \\
\text { own people's } \\
\text { traditional } \\
\text { values }\end{array}$ & 0,14 & $0,29^{* *}$ & - & - & - & - & 0,09 & $0,29^{* *}$ \\
\hline $\begin{array}{l}\text { Культура как } \\
\text { основа елин- } \\
\text { ства народа } \\
\text { Culture as the } \\
\text { basis of the } \\
\text { unity of the } \\
\text { people }\end{array}$ & 0,06 & $0,28^{* *}$ & 0,09 & $0,41^{* *}$ & - & - & - & - \\
\hline $\begin{array}{l}\text { Необхо- } \\
\text { Аимость } \\
\text { знать куль- } \\
\text { туру Аругих } \\
\text { народов } \\
\text { The necessity } \\
\text { of knowing } \\
\text { the other } \\
\text { peoples' } \\
\text { culture }\end{array}$ & 0,04 & $-0,21^{*}$ & - & - & - & - & - & - \\
\hline
\end{tabular}




\begin{tabular}{|c|c|c|c|c|c|c|c|c|}
\hline $\begin{array}{l}\text { Праздно- } \\
\text { вание зна- } \\
\text { менательных } \\
\text { Аат Аругих } \\
\text { народов } \\
\text { Celebrating } \\
\text { the dates } \\
\text { significant for } \\
\text { other peoples }\end{array}$ & - & - & 0,11 & $0,55^{* *}$ & 0,23 & $0,22^{*}$ & - & - \\
\hline $\begin{array}{l}\text { Знание тра- } \\
\text { Аиций и обы- } \\
\text { чаев своего } \\
\text { народа } \\
\text { Knowledge of } \\
\text { own people's } \\
\text { traditions and } \\
\text { customs }\end{array}$ & - & - & 0,11 & $-0,39 * *$ & - & - & - & - \\
\hline $\begin{array}{l}\text { Необхо- } \\
\text { Аимость } \\
\text { прививать } \\
\text { младшему } \\
\text { поколению } \\
\text { традицион- } \\
\text { ные ценности } \\
\text { The neces- } \\
\text { sity of instilling } \\
\text { traditional } \\
\text { values in } \\
\text { the younger } \\
\text { generation }\end{array}$ & - & - & - & - & 0,18 & $0,38 * *$ & - & - \\
\hline & \multicolumn{2}{|c|}{$\begin{array}{c}R^{2}=0,24 \\
F=7,45 \\
p<0,001\end{array}$} & \multicolumn{2}{|c|}{$\begin{array}{l}\mathrm{R}^{2}=0,30 ; \\
F=10,41 ; \\
\mathrm{P}<0,001\end{array}$} & \multicolumn{2}{|c|}{$\begin{array}{l}R^{2}=0,23 \\
F=10,76 \\
P<0,001\end{array}$} & \multicolumn{2}{|c|}{$\begin{array}{c}\mathrm{R}^{2}=0,09 \\
\mathrm{~F}=6,75 \\
\mathrm{p}<0,01\end{array}$} \\
\hline
\end{tabular}




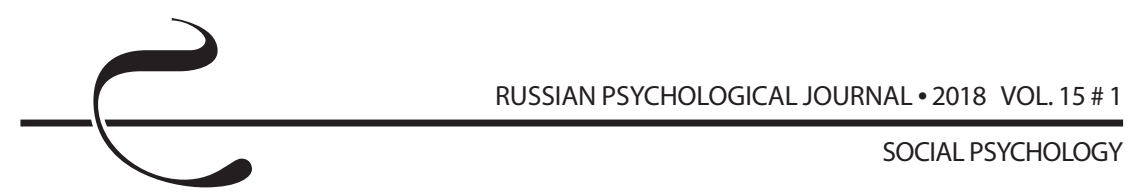

Как видно из таблицы 3, удовлетворенность жизнью представителей титульных этнических групп в обеих странах детерминирована субъективной оценкой степени включенности в культуру и традиции своего народа. Интерес к культуре других народов в выборке русских подрывает удовлетворенность. Показатели $\mathrm{R}^{2}$ говорят о небольшой силе данной предикции, т. К. только $14 \%$ и $6 \%$ вариаций зависимой переменной объясняются названными характеристиками.

Характеристики отношений к этносу и культуре в большей степени обусловливают переживание счастья представителей титульных этнических групп. Сходство выражается и в том, что сильным предиктором (соответственно $10 \%$ и $5 \%$ ) счастья у русских в России и казахов в Казахстане является представление о культуре как основе единства народа.

Обратимся к данным о предикторах психологического благополучия. Прежде всего, обращает внимание факт достаточно сильной его предикции в трех этнических группах и относительно слабой - в группе русских, проживающих в Казахстане. Очевидно, этой части выборки свойственны другие детерминанты психологического благополучия.

\section{Обсуждение результатов}

Результаты сравнительного анализа ценностей показали, что, невзирая на различия выраженности некоторых ценностей, обнаруживается сходство культурных универсалий у представителей титульных этносов и меньшинств. Это вовсе не случайно: подобные результаты были обнаружены в исследовании приверженности европейских мигрантов (разных возрастов и времени миграции) ценностям страны проживания в соотнесении с ценностями страны рождения, где оказалось более сильное сходство со страной проживания [21]. Как видно из приведенных данных, показатели значимости ценностей российских русских более гомогенны, нежели у казахов. Русским свойственно придавать более весомое значение свободе развивать собственные идеи (самостоятельности мысли), избеганию причинения вреда или огорчений Другим (межличностная конформность) и стремлению к равенству и справедливости.

Как видно из представленных данных, русское меньшинство Казахстана демонстрирует более высокий уровень приверженности свободе определять собственные действия и контролю над людьми. Последнее, очевидно, является своеобразным заимствованием от группы большинства Казахстана. Русское большинство в России демонстрирует более высокий уровень ценности толерантности. Небезынтересны и данные, в соответствии с которыми у россиян более выражены коллективистские культурные стратегии. Возможно, для русского меньшинства Казахстана более характерны индивидуалистические 
культурные стратегии, что может быть связано с консервацией культуры. Более высокие показатели коллективистских стратегий ранее нами обнаруживались у казахов [14].

При сопоставлении ценностей русских (Россия) и казахов (Казахстан) выяснилось, что ценности власти - контроль над людьми и контроль материальных ресурсов - более выражены у казахов. Культурные универсалии схожи. В остальном все ценности находятся в зоне сходства средних величин. Подобные результаты в современной ситуации обнаруживаются довольно часто. Даже при сравнении корейцев с европейскими американцами выяснилось отсутствие различий коллективизма, невзирая на столь явные различия культур [19].

Исходя из данных, можно сказать, что русские и казахи в Казахстане не отличаются ни по одной из обобщенных характеристик ценностей Шварца $[29,30]$. Это, возможно, создает весомую ценностную основу для межэтнического сотрудничества и согласия.

Из представленных результатов также видно, что большинство ценностей во всех четырех выборках имеют признаки сходства. Различия сконцентрированы вокруг узкого круга ценностей.

У представителей титульной нации более весом показатель ценности «самостоятельность: мысли», а у групп меньшинств этот показатель значимо ниже в обоих случаях, т. е. и казахское, и русское меньшинства демонстрируют относительно низкие показатели свободы мысли, идей.

Между тем, ценности заботы, чувства долга, безопасности социальной, самостоятельности в поступках являются высшими для всех выборок и характеризуют их представителей как склонных к социальному фокусу ценностей в противовес личностному. Возможно, в этом проявляются их общие коллективистские устремления, что будет подробно проанализировано в наших следующих работах.

Как видно из таблицы 2, среди ценностных предикторов различных характеристик благополучия особенно выделяется ценность «самостоятельность: мысли». Ее ведущая роль в детерминации счастья выявлена в трех выборках (русских и казахов России и казахов Казахстана), и психологического благополучия - в двух выборках казахов. Очевидно, свобода развивать собственные идеи и способности как возможность и ценность выступает таким регулятором поведения субъекта, благодаря которому возможны достижение психологического благополучия и переживание счастья. Статус самостоятельности поступков здесь неоднозначен. Так, свобода определять собственные действия как ценность у русских положительно детерминирует в значительной степени (31\% вариаций) проявления психологического благополучия, а у титульной группы Казахстана отрицательно обусловливает (6\% вариаций) переживания счастья. 


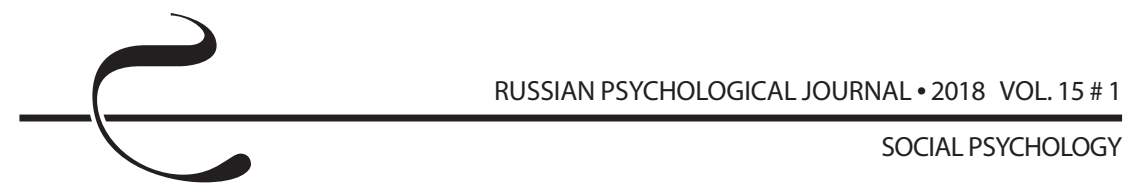

Таким образом, сильная (определяющая) предикция счастья и психологического благополучия ценностью «самостоятельность: мысли» свидетельствует скорее об универсальной ее значимости для субъективного благополучия представителей разных этнических групп и наций. Более всего ценности вносят вклад в вариации психологического благополучия, что не случайно, поскольку эта характеристика субъективного благополучия предполагает отношение к бытию, прежде всего, в его ценностносмысловой проекции.

Изучение отношения к культуре как предиктора характеристик субъективного благополучия позволило выявить неоднозначную картину.

Оппозиционность субъективной оценки включенности в культуру своего народа и интерес к культуре других народов как предикторов удовлетворенности жизнью у русских выражены в достаточно высокой степени. Очевидно, выраженность того и другого одновременно является весомым фактором снижения субъективного благополучия в части удовлетворенности жизнью, возможно из-за диссонансных отношений между этими переменными (включенность в культуру своего народа и интерес к культуре других народов), хотя, казалось бы, очевидной конфликтности между ними на первый взгляд не обнаруживается. Возможно, включенность в культуру своего народа оставляет мало места для интереса к культуре Других. Поэтому, чем сильнее включенность в культуру своего народа и меньше интерес к культуре Других, тем выше удовлетворенность жизнью. У представителей нетитульных этнических групп предикторы удовлетворенности не выявлены.

Детерминантами счастья у казахов являются частота празднования знаменательных дат (положительно) и интерес к культуре других народов (отрицательно). Из этого следует, что причастность к эмоционально окрашенным событиям (положительно) в жизни других народов способствует переживанию счастья, а интерес к культуре Других снижает его, что, очевидно, связано с несколько иными отношениями (например, в виду оппозиционности включения в культуру своего и чужого народа).

Небольшая часть вариаций счастья обусловлена отношением к культуре и этническим характеристикам представителей нацменьшинств. Так, предиктором счастья у казахов, проживающих в России, выступает позитивное отношение к замещению традиционных ценностей европейскими ценностями, а у русских в Казахстане - соблюдение традиций и обычаев своего народа. Иначе говоря, русское меньшинство в Казахстане демонстрирует зависимость вариаций счастья от фиксации и концентрации на прошлом народа, на традиционных характеристиках культуры, в то время как у российских казахов, наоборот, реализуется «выход» на понимаемую, очевидно, сквозь призму средств массовой информации, общеевропейскую культуру. 
Как видно из таблицы 3, психологическое благополучие русских детерминировано такими показателями, как следование традиционным ценностям, представление о культуре как основе для единства народа; подрывает его субъективная оценка необходимости знать культуру других народов. Психологическое благополучие казахов, проживающих в России, детерминировано частотой празднований знаменательных национальных праздников, представлением о важности культуры для единства народа, и оценкой своих знаний о традициях и обычаях своего народа. Очевидно, концентрация представлений вокруг традиционных праздников и внешних элементов национальной культуры национального меньшинства позволяет сохранять определенный психологический баланс, что и способствует сохранению благополучия. Психологическое благополучие представителей титульной нации Казахстана детерминировано стремлением передать младшему поколению традиционные ценности и активным участием в празднованиях знаменательных для своего народа дат. Наконец, следование традиционным ценностям у представителей русского меньшинства Казахстана также является предиктором психологического благополучия, что связано со стабилизирующей ролью этих ценностей, по сути, обеспечивающих эффективную социально-психологическую адаптацию. Таким образом, психологическое благополучие во всех выборках обусловлено параметрами, характеризующими позитивное отношение к традиционной культуре своего народа. Резюмируя сказанное, можно отметить, что в изучаемых странах обнаруживаются две противоположные тенденции - с одной стороны усиливаются тенденции этнической консолидации, обращение к традиционным для этнических групп ценностям, а с другой, - склонность к установлению добрососедских отношений титульной группы с другими этническими группами, характеризующая принятие элементов мультикультурализма как факторов сохранения субъективного благополучия.

\section{Заключение}

Из результатов проведенного исследования следует, что ценности и отношение к этнической культуре и традициям выступают сильными предикторами различных характеристик субъективного благополучия личности. Наиболее значима их роль для выраженности психологического благополучия - того компонента субъективного благополучия личности, который характеризуется со стороны ее осмысленного, позитивного, комфортного в отношениях с Другими и автономного бытия. Эти данные говорят в пользу того, что отношение к культуре и традициям обусловливают глубинные основания субъективного благополучия, те его характеристики, которые 


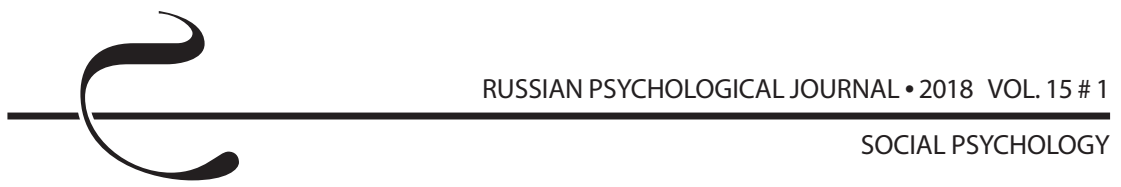

формируются относительно поздно и являются более стабильными по отношению к ситуативным изменениям.

Исходя из анализа предикторов, можно сделать вывод о менее выраженных этнических и более выраженных национальных различиях в предикции субъективного благополучия ценностями или отношением к традициям. Это свидетельствует об иной настройке в ценностной детерминации субъективного благополучия. Наиболее важными предикторами субъективного благополучия являются позитивное отношение к культуре как основе единства народа и степень включенности в культуру и традиции своего народа, а интерес/знание к культуре других народов подрывает субъективное благополучие. Последнее требует детального анализа, поскольку проявляется в трех этнических группах и, очевидно, не служит целям межэтнического и межкультурного взаимодействия.

Ценностная детерминация удовлетворенности жизнью и счастья более весома и более определена у представителей титульных этнических групп России и Казахстана, а психологическое благополучие детерминировано одинаково сильно, но разными ценностями во всех группах.

Различия выраженности ценностей изучаемых групп сконцентрированы вокруг блока ценностей «открытость изменениям» (готовность к новым и преобразующим идеям), ценностей власти. Практически отсутствуют различия значимости ценностей сохранения. Иначе говоря, существуют весомые ценностные основания для позитивного и продуктивного межэтнического и межнационального взаимодействия, которые основаны на стремлении к традиционности, безопасности и отчасти к согласию, что относится к ценностям консерватизма. Кроме того, наивысшую выраженность в ценностной иерархии практически всех групп занимают ценности самостоятельности (мыслей и поступков), безопасности (личной и социальной), заботы и чувства долга, - характеризующие достаточно выраженные противоречивые отношения - проявлений личностного и социального фокусов, что может выражаться во внутренней напряженности испытуемых и становиться фактором снижения благополучия.

\section{Литература}

1. Журавлев А. Л., Юревич А. В. Коллективные смыслы как предпосылка личного счастья // Психологический журнал. - 2014. - Т. 35, № 1. C. 5-15.

2. Тарасова Л. Е. Представления о счастье в фольклорном и обыденном сознании // Проблемы социальной психологии личности : Межвуз. сб. науч. тр. - Саратов : Изд-во Сарат. ун-та, 2011. - Вып. 9. - С. 60-67.

3. Джидарьян И. А. Психология счастья и оптимизма. - М. : Изд-во ИПРАН, 2013. -268 c. 
4. Sheldon K. M. Optimal Human Being: An Integrated Multi-Level Perspective. - NY : Routledge, 2016. - 239 p.

5. Sheldon K.M., Cheng C., Hilpert J. Understanding Well-Being and Optimal Functioning: Applying the Multilevel Personality in Context (MPIC) Model // Psychological Inquiry. - 2011. -Vol. 22, Issue 1. - P. 1-16. DOI: 10.1080/1047840X.2011.532477

6. Шамионов Р.М. Этнокультурные факторы субъективного благополучия личности // Психологический журнал. - 2014. - Т. 35, № 4. - С. 68-81.

7. Сухарев А. В. Этнофункциональная парадигма в психологии: Теория развития и эмпирические исследования. - М. : Изд-во ИП РАН, 2008. - 576 с.

8. Журавлёв А. Л., Дробышева Т. В. Ценностные ориентации формирующейся личности в разные периоды развития российского общества // Психологический журнал. - 2010. - Т. 31, № 5. - С. 5-16.

9. Чиксентмихайи М. Поток: Психология оптимального переживания / пер. с англ. - М. : Смысл ; Альпина нон-фикшн, 2011. - 461 с.

10. Taormina R. J., Shamionov R. M. A New Measure of Traditional Values Across Cultures: China and Russia Compared // Psychological Thought. - 2016. Vol. 9, № 2. - P. 197-221. DOI: 10.5964/psyct.v9i2.202

11. Лебедева Н. М. Ценности культуры и отношение к инновациям в России и Китае // Альманах современной науки и образования. - 2009. - № 11, 4. 2. - C. 188-192. - URL: www.gramota.net/materials/1/2009/11-2/69.html (дата обращения 24.01.2018).

12. Лебедева Н. М. Ценности и отношение к инновациям: межкультурные различия // Психологический журнал. - 2009. - Т. 30, № 6. - С. 81-92.

13. Шамионов Р. М. Взаимосвязь групповых ценностей и субъективного благополучия представителей контактирующих этносов (на примере Поволжья) // Вектор науки Тольяттинского государственного университета. Серия: Педагогика, психология. - 2011. - № 4. - С. 307-309.

14. Шамионов Р. М. Групповые ценности и установки как предикторы психологического благополучия русских и казахов // Психологические исследования. - 2014. - Т. 7, № 35. - C. 12. - URL: http://psystudy.ru/index. php/num/2014v7n35/999-shamionov35.html (дата обращения: 10.02.2018).

15. Шамионов Р. М. Уверенность в себе и базовые убеждения как предикторы субъективного благополучия русских и казахов // Психологические исследования. - 2016. - Т. 9, № 45. - С. 5. - URL: http://psystudy.ru/ index.php/num/2016v9n45/1235-shamionov45.html (дата обращения: 10.02.2018).

16. Dzuka J., Dalbert C., Schmitt M. Viera v spravodlivý svet a jej ochranná funkcia vo vztahu k subjektívnej pohode: výskum špecifických kopingových reakcií // Ceskoslovenska psychologie. - 2013. - Vol. 57 (1). - P. 64-72. - URL: http:// cspsych.psu.cas.cz/result.php?id=789 


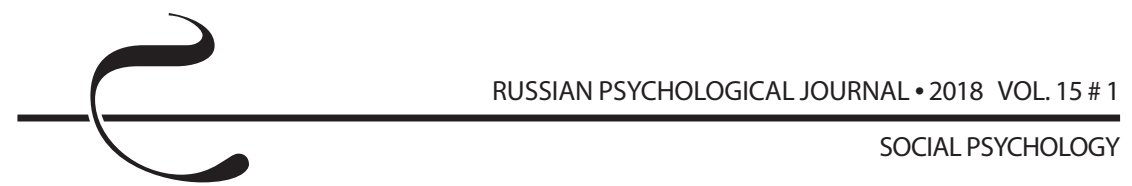

17. Chirkov V. I., Ryan R. M., Willness C. Cultural Context and Psychological Needs in Canada and Brazil: Testing a Self-Determination Approach to the Internalization of Cultural Practices, Identity and Well-Being // Journal of Cross-Cultural Psychology. - 2005. - Vol. 36, Issue 4. - P. 423-443. DOI: 10.1177/0022022105275960

18. Inglehart R. Modernization and Postmodernization: Cultural, Economic, and Political Change in 43 Societies. - Princeton : Princeton University Press, 1997. - 464 p.

19. Park H., Joo J., Quiroz B., Greenfield P. M. Sociodemographic Factors Influence Cultural Values: Comparing European American With Korean Mothers and Children in Three Settings - Rural Korea, Urban Korea, and Los Angeles // Journal of Cross-Cultural Psychology. - 2015. - Vol. 46, Issue 9. - P. 1131-1149. DOI: $10.1177 / 0022022115600258$

20. Rokeach M. Understanding Human Values: Individual and Societal. - N. Y. : Free Press, 1979. - $322 \mathrm{p}$.

21. Rudnev M. Value Adaptation Among Intra-European Migrants: Role of Country of Birth and Country of Residence // Journal of Cross-Cultural Psychology. 2014. - Vol. 45, Issue 10. - P. 1626-1642. DOI: 10.1177/0022022114548482

22. Tartakovsky E., Walsh S. D. Testing a New Theoretical Model for Attitudes Toward Immigrants: The Case of Social Workers' Attitudes Toward Asylum Seekers in Israel // Journal of Cross-Cultural Psychology. - 2016. - Vol. 47, Issue 1. - P. 72-96. DOI: 10.1177/0022022115613860

23. Гриценко В. В. Социально-психологическая адаптация переселенцев в России. - М. : Изд-во ИП РАН, 2002. - 252 с.

24. Diener E. Culture and Well-being : The Collected Works of Ed Diener. - Dordrecht : Springer, 2009. - 304 p. DOI: 10.1007/978-90-481-2352-0

25. Diener E., Oishi S., Lucas R. E. Personality, Culture, and Subjective WellBeing: Emotional and Cognitive Evaluations of Life // Annual Review of Psychology. - 2003. - Vol. 54 (1). - P. 403-425. DOI: 10.1146/annurev. psych.54.101601.145056

26. Шамионов Р. М. Соотношение степени эмоциональной приверженности к этнической группе, религиозности и гражданской идентичности и субъективного благополучия личности // Вестник Удмуртского университета. Серия Философия. Психология. Педагогика. - 2016. - Т. 26, Вып. 4. - С. 107-112.

27. Осин Е. Н., Леонтьев Д. А. Апробация русскоязычных версий двух шкал экспресс-оценки субъективного благополучия // Материалы III Всероссийского социологического конгресса. - М. : Изд-во Института социологии PAH, 2008. - URL: http://www.isras.ru/abstract_bank/1210190841.pdf (дата обращения: 30.01.2018). 
28. Жуковская Л. В., Трошихина Е. Г. Шкала психологического благополучия К. Рифф // Психологический журнал. - 2011. - Т. 32, № 2. - С. 82-93.

29. Швари Ш., Бутенко Т. П., Седова Д. С., Липатова А. С. Уточненная теория базовых индивидуальных ценностей: применение в России // Психология. Журнал Высшей школы экономики. - 2012. - Т. 9, № 1. - С. 43-70. - URL: https://psy-journal.hse.ru/data/2013/10/30/1283379255/Schwartz_et_al_902pp43-70.pdf (дата обращения: 30.01.2018).

30. Schwartz S. H., Butenko T. Values and behavior: Validating the refined value theory in Russia // European Journal of Social Psychology. - 2014. - Vol. 44, Issue 7. - P. 799-813. DOI: 10.1002/ejsp.2053

\section{References}

1. Zhuravlev A. L., Yurevich A. V. Collective meanings as a precondition for personal happiness. Psikhologicheskii zhurnal, 2014, V. 35, no. 1, pp. 5-15 (in Russian).

2. Tarasova L. E. Views of happiness in folklore and everyday consciousness. In: Problemy sotsial'noi psikhologii lichnosti [Problems of the social psychology of personality]. Saratov, Saratov State University Publ., 2011, V. 9, pp. 60-67.

3. Dzhidar'yan I. A. Psikhologiya schast'ya ioptimizma [Psychology of happiness and optimism]. Moscow, Institute of Psychology, RAS Publ., 2013. 268 p.

4. Sheldon K. M. Optimal human being: An integrated multi-level perspective. NY, Routledge, 2016. 239 p.

5. Sheldon K. M., Cheng C., Hilpert J. Understanding well-being and optimal functioning: applying the Multilevel Personality in Context (MPIC) model. Psychological Inquiry, 2011, V. 22, Issue 1, pp. 1-16. DOI: 10.1080/1047840X.2011.532477

6. Shamionov R. M. Ethno-cultural factors of subjective well-being. Psikhologicheskii zhurnal, 2014, V. 35, no. 4, pp. 68-81 (in Russian).

7. Sukharev A. V. Etnofunktsional'naya paradigma v psikhologii: Teoriya razvitiya i empiricheskie issledovaniya [Ethnofunctional paradigm in psychology: Development theory and empirical research]. Moscow, Institute of Psychology, RAS Publ., 2013. 576 p.

8. Zhuravlev A. L., Drobysheva T. V. Value orientations of a forming personality in various developmental periods of Russian society. Psikhologicheskii zhurnal, 2010, V. 31, no. 5, pp. 5-16 (in Russian).

9. Csikszentmihalyi M. Flow: The psychology of optimal experience (Russ. ed.: Chiksentmikhaii M. Potok: Psikhologiya optimal'nogo perezhivaniya. Moscow, Smysl, Al'pina non-fikshn Publ., 2011. 461 p.).

10. Taormina R. J., Shamionov R. M. A new measure of traditional values across cultures: China and Russia compared. Psychological Thought, 2016, V. 9, no. 2, pp. 197-221. DOI: 10.5964/psyct.v9i2.202 
11. Lebedeva N. M. Values of culture and attitudes to innovations in Russia and China. Al'manakh sovremennoi nauki i obrazovaniya - Almanac of Modern Science and Education, 2009, no. 11, Part 2, pp. 188-192 (in Russian). Available at: www.gramota.net/materials/1/2009/11-2/69.html (Accessed 24 January 2018).

12. Lebedeva N. M. Values and attitudes to innovations: intercultural differences. Psikhologicheskii zhurnal, 2009, V. 30, no. 6, pp. 81-92 (in Russian).

13. Shamionov R. M. The relationship between group values and subjective wellbeing among representatives of contacting ethnic groups (case study of the Volga region). Vektor nauki Tol'yattinskogo gosudarstvennogo universiteta. Seriya: Pedagogika, psikhologiya - Science Vector of Togliatti State University. Series: Pedagogy, Psychology, 2011, no. 4, pp. 307-309 (in Russian).

14. Shamionov R. M. Group values and attitudes as predictors of psychological well-being among Russians and Kazakhs. Psikhologicheskie issledovaniya Psychological Studies, 2014, V. 7, no. 35, pp. 12 (in Russian). Available at: http://psystudy.ru/index.php/num/2014v7n35/999-shamionov35.html (Accessed 10 February 2018).

15. Shamionov R. M. Self-confidence and basic beliefs as predictors of subjective well-being among Russians and Kazakhs. Psikhologicheskie issledovaniya Psychological Studies, 2016, V. 9, no. 45, pp. 5 (in Russian). Available at: http://psystudy.ru/index.php/num/2016v9n45/1235-shamionov45.html (Accessed 10 February 2018).

16. Dzuka J., Dalbert C., Schmitt M. Viera v spravodlivý svet a jej ochranná funkcia vo vztahu ksubjektívnej pohode: výskum špecifických kopingových reakcií. Ceskoslovenska psychologie, 2013, V. 57 (1), pp. 64-72. Available at: http://cspsych.psu.cas.cz/result.php?id=789 (Accessed 10 February 2018).

17. Chirkov V. I., Ryan R. M., Willness C. Cultural context and psychological needs in Canada and Brazil: Testing a self-determination approach to the internalization of cultural practices, identity and well-being. Journal of Cross-Cultural Psychology, 2005, V. 36, Issue 4, pp. 423-443. DOI: $10.1177 / 0022022105275960$

18. Inglehart R. Modernization and postmodernization: Cultural, economic, and political change in 43 societies. Princeton, Princeton University Press, 1997.464 p.

19. Park H., Joo J., Quiroz B., Greenfield P. M. Sociodemographic factors influence cultural values: Comparing European American with Korean mothers and children in three settings - rural Korea, urban Korea, and Los Angeles. Journal of Cross-Cultural Psychology, 2015, V. 46, Issue 9, pp 1131-1149. DOI: 10.1177/0022022115600258

20. Rokeach M. Understanding human values: individual and societal. N. Y., Free Press, 1979. $322 \mathrm{p}$. 
21. Rudnev M. Value adaptation among intra-European migrants: Role of country of birth and country of residence. Journal of Cross-Cultural Psychology, 2014, V. 45, Issue 10, pp. 1626-1642. DOI: 10.1177/0022022114548482

22. Tartakovsky E., Walsh S. D. Testing a new theoretical model for attitudes toward immigrants: The case of social workers' attitudes toward asylum seekers in Israel. Journal of Cross-Cultural Psychology, 2016, V. 47, Issue 1, pp. 72-96. DOI: 10.1177/0022022115613860

23. Gritsenko V.V. Sotsial'no-psikhologicheskaya adaptatsiya pereselentsev v Rossii [Socio-psychological adaptation among immigrants in Russia]. Moscow, Institute of Psychology, RAS Publ., 2002. 252 p.

24. Diener E. Culture and well-being: The collected works of Ed Diener. Dordrecht, Springer, 2009. 304 p. DOI: 10.1007/978-90-481-2352-0

25. Diener E., Oishi S., Lucas R. E. Personality, culture, and subjective well-being: Emotional and cognitive evaluations of life. Annual Review of Psychology, 2003, V. 54 (1), pp. 403-425. DOI: 10.1146/annurev.psych.54.101601.145056

26. Shamionov R. M. The relationship among the degree of emotional adherence to an ethnic group, religiosity, civic identity, and subjective well-being. Vestnik Udmurtskogo universiteta. Seriya Filosofiya. Psikhologiya. Pedagogika Bulletin of Udmurt University. Series: Philosophy. Psychology. Pedagogy, 2016, V. 26, Issue 4, pp. 107-112 (in Russian).

27. Osin E. N., Leont'ev D. A. Aprobatsiya russkoyazychnykh versii dvukh shkal ekspress-otsenki sub"ektivnogo blagopoluchiya [Testing of the Russian versions of two scales of the rapid assessment of subjective well-being]. Materialy III Vserossiiskogo sotsiologicheskogo kongressa [Proc. the 3rd All-Russian Sociological Congress]. Moscow, Institute of Sociology, Russian Academy of Sciences Publ., 2008. Available at: http://www.isras.EN/ abstract_bank/1210190841.pdf (Accessed 30 January 2018).

28. Zhukovskaya L. V., Troshikhina E. G. The Ruff Scales of Psychological WellBeing. Psikhologicheskii zhurnal, 2011, V. 32, no. 2, pp. 82-93 (in Russian).

29. Shvarts Sh., Butenko T. P., Sedova D. S., Lipatova A. S. The refined theory of basic individual values: Applying in Russia. Psikhologiya. Zhurnal Vysshei shkoly ekonomiki - Psychology, Journal of the Higher School of Economics, 2012, V. 9, no. 1, pp. 43-70 (in Russian).

30. Schwartz S. H., Butenko T. Values and behavior:Validating the refined value theory in Russia. European Journal of Social Psychology, 2014, V. 44, Issue 7, pp. 799-813. DOI: 10.1002/ejsp.2053 